\title{
LEITURA EM LÍNGUA ESTRANGEIRA NO ENSINO MÉDIO: uma experiência em Roraima
}

\author{
READING IN FOREIGN LANGUAGE IN SECONDARY EDUCATION: an experi- \\ ence in Roraima
}
LECTURA EN LENGUA EXTRANJERA EN LA ENSEÑANZA MEDIA: una experi- encia en Roraima

\author{
Maria Francisca da Silva \\ Professora Mestra da Universidade Federal do Maranhão - Campus São Bernardo. \\ Doutoranda em Letras Neolatinas Espanhol (UFRJ). \\ masilva8@yahoo.com.br
}

Maria Mercedes Riveiro Quintans Sebold Professora Doutora da Universidade Federal do Rio de Janeiro (UFRJ). m.sebold@yahoo.com.br

\begin{abstract}
RESUMO: Este artigo tem por objetivos verificar a relevância do trabalho de leitura com bases nas estratégias de leitura interacional no Ensino Médio e avaliar se o uso lúdico do texto literário facilita a aprendizagem em espanhol língua estrangeira. Parte-se das hipóteses de que há pouca recorrência do texto literário no ensino de língua estrangeira e de que a leitura do texto literário com estratégias interacionais contribui para a facilitação da de sua aprendizagem. Para tanto, utilizo os subsídios teóricos de leitura, da análise do discurso e gênero discursivo, do texto literário e da estrutura do conto. Os resultados indicam caminhos para a abordagem didática do texto literário (doravante TL) e ampliam as reflexões sobre seu uso nas aulas espanhol, principalmente em região de fronteira como a nossa em Roraima.
\end{abstract}

PALAVRAS-CHAVE: Leitura. Estratégias interacionais. Texto literário. Ensino de espanhol.

ABSTRACT: This article aims to verify the relevance of reading activities based on interactional reading strategies in high school and assess if use of the literary text facilitates the learning of Spanish as a foreign language. I begin with the hypothesis that there is little recourse to literary text in the teaching of foreign language and that the reading of literary texts based on interactional strategies contributes to facilitate foreign language learning. To that end, I make use of theoretical reading base, discourse and discourse genre analysis, the literary text and the story structure. The results indicate paths for the teaching approach of the literary text and extend the reflections on the use of the literary text (LT) in Spanish classes, especially in the border region with Roraima, where we are located.

KEYWORDS: Reading. Interactional Strategies. Literary Text. Spanish Teaching.

RESUMEN: Este artículo tiene como objetivo verificar la relevancia del trabajo de la lectura con bases en estrategias de lectura interactiva en la escuela secundaria y evaluar si el uso lúdico del texto literario facilita el aprendizaje de español como lengua extranjera. Se inicia, con la hipótesis de que hay poca recurrencia texto literario en la enseñanza de lenguas extranjeras y la lectura de textos literarios con las estrategias de interacción contribuyen a la facilitación del aprendizaje de lenguas extranjeras. Para ello, he utilizado la lectura de subsidios teóricos sobre el análisis del discurso y el género discursivo, el texto literario y la estructura del cuento. Los resultados indican los caminos para el enfoque de la enseñanza del texto literario y amplían las reflexiones sobre el uso del texto literario (desde ahora TL) en clases de español, sobre todo en la región fronteriza como la nuestra en Roraima.

PALABRAS CLAVE: Lectura. Estrategia interacional. Texto literario. La enseñanza del español.

Artigo recebido em janeiro de 2015

Aprovado em março de 2015

Cad. Pes., São Luís, v. 22, n. 1, jan./abr. 2015 
LEITURA EM LÍNGUA ESTRANGEIRA | Maria Francisca da Silva e Maria Mercedes R. Quintans Sebold

\section{1 | INTRODUÇÃO}

Neste trabalho, proponho-me a discutir o uso do texto literário no ensino de espanhol como língua estrangeira, no Ensino Médio do município de Alto Alegre/Roraima, a partir de uma experiência didática com o uso do conto nas aulas da referida disciplina, utilizando os subsídios de análise de leitura propostos por Kato (2010), Coracini (2002), Kleiman (1992). Também utilizei os pressupostos teóricos da análise do discurso e gênero discursivo, a partir de Marcuschi (2011), Charaudeau (2009) e do texto literário de Dominique Maingueneau (2001) e estrutura do conto de Propp (1970). Tem sua metodologia com foco na pesquisa etnográfica, conforme Demo (1992), a partir da coleta de dados qualitativos no grupo de aprendizes do Ensino Médio em escola pública de Alto Alegre/Roraima. Assim como, a ótica discursiva, proposta pelo modelo de entrevista aplicado, conforme (ROCHA; DAHER; SANT'ANNA, 2004).

Parte-se das hipóteses de que há pouca recorrência do texto literário no ensino de língua estrangeira e de que a leitura do texto literário com estratégias interacionais contribui para a facilitação da aprendizagem em língua estrangeira. A aplicação da atividade didática serviu de base para confirmar ou refutar as hipóteses propostas no inicio desse trabalho, que tem como objetivo:

a) verificar a relevância do trabalho de leitura com bases nas estratégias de leitura interacional no Ensino Médio;

b) avaliar se o uso lúdico do texto literário facilita a aprendizagem em espanhol língua estrangeira.

Diante do assunto, inferi quanto ao recorte para este artigo, expressando somente as possibilidades inferenciais em relação aos aprendizes:

a) a experiência com o texto literário se restringe à escola para fins de avaliação;

b) uma boa experiência didática com o texto literário pode reverter a imagem e as práticas anteriormente construídas.

O trabalho destacará a relevância de uma prática didática direcionada para a compreensão do texto literário como facilitador da aprendizagem de Língua Estrangeira. Ele se constitui um recorte de minha Dissertação de Mestrado, defendida em agosto de 2012, intitulada "Uma Experiência de Leitura do Gênero "Conto" nas Aulas de Espanhol Língua Estrangeira numa Escola Pública de Roraima", em que coloco em relevo a interação dos aprendizes numa atividade de leitura com o uso do conto.

Espero que o trabalho contribua para ampliar as reflexões sobre o uso do texto literário nas aulas de Espanhol, assim como, que colabore com um olhar reflexivo dentre muitos existentes para que surjam outros olhares a partir dessa perspectiva apresentada.

\section{2 | APORTE TEÓRICO}

As pesquisas de Kleiman (1992), Kato (2007; 2010), Moita Lopes (2002), Coracini (2002), Serrani (2005) têm contribuído para ampliação do conceito de linguagem, por conseguinte, da leitura, no Brasil. Nessas pesquisas, observa-se as principais concepções de leitura que vão desde a abordagem com foco no texto, a leitura com foco no leitor e o conceito de leitura relacionado à interação entre os componentes do ato da comunicação escrita - interacional. O leitor, portador

\footnotetext{
${ }_{1}^{1}$ Orientadora, Doutora Maria Mercedes Riveiro Quintans Sebold e Co-Orientada pelo Doutor Pedro Paulo Garcia Ferreira Catharina - UFRJ/2012.
} 
LEITURA EM LÍNGUA ESTRANGEIRA | Maria Francisca da Silva e Maria Mercedes R. Quintans Sebold

de esquemas mentais socialmente adquiridos, acionaria seus conhecimentos prévios e os confrontaria com os dados do texto, elaborando o sentido.

Nessa concepção, o bom leitor é aquele capaz de percorrer as marcas deixadas pelo autor para chegar à formulação de suas ideias e intenções. "A leitura se processa na interação textoleitor ou numa vertente mais recente, autor - texto - leitor" (CORACINI, 2002, p. 13).

Diante desse pressuposto interacional, Kleiman argumenta sobre os direcionamentos dados aos conhecimentos necessários para compreensão do texto, isto é, na ativação do conhecimento prévio "o leitor utiliza na leitura o que ele já sabe, o conhecimento adquirido ao longo de sua vida" (KLEIMAN, 1992, p. 13).

O conhecimento linguístico desempenha um papel central no processamento do texto, o qual corresponde ao agrupamento das palavras em unidades significativas, constituindo frases. $\mathrm{O}$ processo de segmentação está relacionado à organização que o leitor faz ao associar sujeito e verbos descontínuos, construindo a compreensão do texto. Assim como o conhecimento linguístico, o conhecimento textual também faz parte do conhecimento prévio necessário à compreensão textual (KLEIMAN, 1992, p. 14).

O processo de leitura pressupõe que o leitor possua um conhecimento textual prévio na identificação dos diversos tipos de textos e de suas formas discursivas. Tais estruturas desdobramse em tipos textuais conhecidos como narração, argumentação, exposição, descrição e injunção, que são designados por sua construção teórica e definidos por sua natureza linguística de composição-aspectos lexicais, sintáticos, tempos verbais, relações lógicas, estilos (MARCUSCHI, 2011, p. 154).

Destaco aqui, a relevância do trabalho com os pressupostos interacionais, isto é, a interação entre "autor - texto - leitor" (CORACINI, 2002), subsidiada pelo professor através de marcas lingüísticas que serão observadas no texto, através do ativação do conhecimento prévio, o conhecimento linguístico, o conhecimento do gênero discursivo (KLEIMAN,1992) assim como outros elementos que subsidiem o discente em sua aprendizagem.

Todos esses pressupostos são tomados neste trabalho como válidos para o processo de leitura em língua estrangeira. Destaco, nesta pesquisa, uma concepção de língua que se realiza em diversos gêneros e sinaliza para um trabalho dinâmico do uso da literatura, isto é, uma abordagem do texto literário em sala de aula de segunda língua voltada para "[...] um trabalho discursivo - contrastivo intra e inter - linguístico, em que as práticas verbais (leitura, escrita, produção oral, escuta e quando couber, tradução) estejam inter-relacionadas." (SERRANI, 2005, p. 47).

O texto literário e não literário se constituem como unidades de significação no momento da leitura, não se constituindo em uma atividade de mera decodificação pelo leitor, conceito que permeia muitas das aulas de ensino de segunda língua. Em se tratando de texto literário, é necessário uma retomada nas noções de gênero textual, neste caso específico, me deterei no gênero narrativo e no conceito de conto, com ênfase nos contos venezuelanos.

A noção de gênero é facilmente usada para referir-se a uma categoria distintiva de discurso de qualquer tipo, falado ou escrito, com ou sem aspirações literárias (MARCUSCHI, 2011, p. 147). O gênero textual refere-se aos textos materializados em situações comunicativas recorrentes. Os gêneros textuais são constituídos por textos que se encontram em nossa vida diária e que apresentam padrões sociocomunicativos característicos, definidos por composições funcionais, objetivos enunciativos e estilos concretamente realizados na integração de forças históricas, sociais, institucionais e técnicas.

Para o conceito de conto, me valho da proposta de Propp (1970), por ter sido o primeiro a tentar definir modelos estruturais da narrativa a partir do estudo da forma (morfologia) e determinar a 
LEITURA EM LÍNGUA ESTRANGEIRA | Maria Francisca da Silva e Maria Mercedes R. Quintans Sebold

a especificidade do gênero (contos "maravilhosos" russos). Desse modelo de Propp, utilizo as categorias universais do conto, nas quais destaco algumas:

Preparação para ação no conto:

a) Situação inicial - introduz o futuro herói ou futura vítima, definindo a composição familiar; faz referência a alguma profecia, estado de prosperidade vigente ou perda; sugere tempo indefinido;

b) situação de ausência - um dos membros se ausenta do lar, criando uma situação de perigo [...].

\section{Ação no conto:}

a) dano ou carência - o anti-herói prejudica um membro da família (ex.: rapto, roubo, assassinato, etc.) ou uma situação de carência que leva o anti-herói a provocar um dano; b) mediação - o dano é divulgado ou a carência é reconhecida como necessária (apelo ao herói para que restabeleça o equilíbrio rompido, ou permissão para que ele vá embora) [...].

É importante que se considere o conto como um gênero e, como tal, com categorias próprias de sua materialidade. Entretanto, muitas vezes na aula de língua estrangeira tais categorias são desconsideradas e o conto passa a ser visto como mero repositório de elementos linguísticos.

Neste trabalho, seleciono um conto venezuelano de Sérgio Dahbar (1983). Este autor surge como escritor nos anos 80 do século $X X$, na oficina de criação literária do Centro de Estudos Latino Americanos Rômulo Gallegos. A temática tratada em seus contos apresenta elementos comuns à realidade do discente brasileiro.

\section{3 | METODOLOGIA}

Esta pesquisa é de cunho etnográfico, com coleta de dados qualitativos, como comprovaremos a seguir. Nesses termos, a observação seguida de registro escrito é muito recorrente, visto que contribui para caracterizar o contexto social da sala de aula (DEMO, 1996). Utilizei essa técnica durante a fase de gravação em áudio e vídeo das aulas de leitura em espanhol língua estrangeira realizadas na sala de aula lócus da pesquisa. Nessa etapa, realizei uma observação direta não estruturada, o que equivale a dizer que registrei, em forma de notas de campo, acontecimentos nas aulas que pudessem vir a revelar algo de relevante na análise dos dados. Buscou-se assim, observar o tema considerando a perspectiva do docente e do aprendiz. Para dar voz ao docente, foi utilizada uma entrevista com base no modelo de Daher (1998). O modelo de entrevista usado na coleta de dados, com os professores, foi baseado nos trabalhos de Daher (1998) que destacou o processo de organização do roteiro de entrevista, no qual, a partir de blocos temáticos, formalizaria os objetivos, os problemas e as hipóteses que levariam à concretização das perguntas. Ao usar a entrevista como ferramenta, concebo-a numa perspectiva enunciativa da linguagem, como um evento dialógico. As respostas dadas às perguntas constroem um texto, sob a ótica discursiva (ROCHA; DAHER; SANT'ANNA, 2004). Através dessa organização da entrevista, o pesquisador em Análise do Discurso levantaria as marcas discursivas que caracterizassem as hipóteses inicialmente previstas durante a pesquisa e/ou ampliaria as possibilidades de verificação de novos rumos ao trabalho em andamento.

Quanto a abordagem com os alunos, foi realizada entrevista sociolinguística antes da aplicação da atividade didática. Outro recurso utilizado foi a verificação dos vídeos gravados durante a aplicação da atividade, com a devida autorização de imagem tanto pelos pais quanto pela direção da escola, através de assinatura de documentos de uso de informações educacionais para fins 
de pesquisa. Para atender a esses requisitos foram usados dois gravadores em espaços distintos da sala e duas câmeras de vídeo que registraram a aplicação de toda a atividade.

O conhecimento da turma para aplicação da atividade passou primeiramente pela verificação do perfil da turma com uso de questionário que foi respondido por todos os aprendizes. A seguir, procedo aos encaminhamentos para realização da atividade.

A aplicação da atividade passou por etapas, isto é, para a coleta de dados qualitativos coletados com uso de parâmetros para aquisição do corpus de pesquisa, como: filmagem da aplicação de proposta didática com aprendizes do $3^{\circ}$ ano do Ensino Médio numa escola pública de Alto Alegre/RR com uso do enfoque interacional; construção de diário de campo durante as coletas; e por fim, análise das transcrições do material coletado e dos documentos recolhidos.

A experiência foi realizada com duas turmas do Ensino Médio Regular com 20 aprendizes em cada turno (vespertino e noturno), com idades entre 16 e 34 anos e dois docentes, ambos formados em Curso de Licenciatura em Espanhol de uma faculdade particular existente no Estado. Para efeito de análise, optei pela turma que apresentou maior envolvimento durante realização da atividade piloto, também com uso do texto literário. A coleta dos dados deu-se nos meses de outubro e novembro de 2011.

\section{4 | METODOLOGIA}

Analiso os dados à luz das considerações levantadas no aporte teórico apresentado anteriormente. Em se tratando de uma pesquisa que versa sobre o trabalho em sala de aula com espanhol língua estrangeira, minha análise dos dados estará centrada em aspectos que delineiem um panorama do uso do texto literário - conto em atividade de leitura.

Como já mencionado, a atividade didática foi realizada em duas turmas do Ensino Médio de uma escola pública de Alto Alegre/RR; porém, como recorte de corpus, optei pela turma do $3^{\circ}$ ano, vespertino, por observar que houve maior interação entre os sujeitos da pesquisa e a atividade proposta. A seguir, descrevo a atividade piloto que já serviu de corpus da pesquisa, pois houve a possibilidade de reflexões sobre a prática didática da leitura do texto literário.

Primeiramente, os grupos receberam o título do conto "Un día de enero", para que levantassem hipóteses sobre o conteúdo do conto. Assim, cada grupo tinha cinco minutos para apresentar sua ideia sobre o conto a ser lido. Alguns aprendizes reclamaram do tempo, por ser pouco para definição de uma narrativa. Durante esse momento, estava disposto um projetor de vídeo com slides sobre a biografia e as obras de Sergio Dahbar, porém o docente não utilizou o material; segundo ele, não houve tempo hábil.

Na sequência, o docente entregou os textos para a leitura e a maioria dos aprendizes começou a ler o conto, com algumas conversas paralelas. Durante a leitura, o docente entregou também uma folha com informações sobre o autor e a obra. A pressão do tempo fez com que o docente entregasse, em seguida, antes do término da leitura do texto, as perguntas de compreensão, sem um tempo para análise do texto pelos grupos, nem uma maior interação entre os aprendizes.

A abordagem do texto literário com foco na construção do conhecimento está diretamente relacionada ao encaminhamento didático de leitura a ser desenvolvido pelo docente no momento da interação em sala de aula. Não obstante, durante todo o planejamento realizado para execução da atividade, o docente assumiu a postura que mantém normalmente ${ }^{2}$, demonstrando que não

\footnotetext{
${ }^{2} \mathrm{O}$ termo normalmente foi aplicado relacionado a postura da prática prescritiva de leitura do docente, sem contribuir para uma leitura interativa por parte dos aprendizes.
} 
houve uma integração entre o que planejou para realizar a atividade e o que foi efetivado na aula de espanhol língua estrangeira (SILVA, 2010). Destaco a seguir, alguns fragmentos dos dados levantados durante aplicação da atividade didática.

A seguir, descrevo a atividade didática com o texto literário, após atividade piloto. Tal atividade também foi aplicada nas duas turmas e com os mesmos docentes, mantendo assim, o parâmetro metodológico para análises dos dados coletados. Para fins de recorte do corpus, aqui destaco excerto da turma do $3^{\circ}$ ano do período vespertino.

O docente inicia a atividade didática distribuindo o texto em espanhol, do conto "Hansel e Gretel" dos Irmãos Grimm, com a chamada dos aprendizes alternando português e espanhol, conforme excerto 1. Não houve, assim, uma relação da atividade didática que seria proposta com a realizada anteriormente, com o uso do conto do autor venezuelano, que tratava de uma situação semelhante (a família desestruturada que abandona os filhos). Nem se fez menção a informações sobre os autores e a obra, que estava disponibilizada na sala através do projetor de slides e de folhas impressas com as informações. A seguir, o docente inicia a atividade mobilizando a participação dos aprendizes, a partir da pontuação do trabalho realizado, de acordo com o excerto 2.

\footnotetext{
Excerto 1 - Docente

Docente - Atenção, atenção voy hacer la llamada, por favor. Hagan silencio! Número un.

Discente.1 - Presente.

Docente - Dos.

Como se verifica, não há um cuidado do docente em utilizar, num mesmo turno de fala, somente uma das línguas. Tal atitude caracteriza e reforça o "portunhol" praticado em sala de aula, quando faltam critérios diante do discurso proferido no contexto educativo do ensino de Língua Estrangeira.
}

Excerto 2 - Docente e aprendizes

Docente - Esa tarea, esas tarea es la última tarea, eh... que vamos hacer con con valor...

Aprendiz.1- vinte pontos

Discente 2- (inint.) cinquenta, docente.

Docente- Não.

Aprendiz.1- cinquenta

Aprendiz.2- quarenta

Aprendiz.3- trinta

Aprendiz.4- quinze

Aprendiz.5- dez

Docente - Son veinte puntos.

Aprendiz.- Professora!

\section{Excerto 3 - Docente e aprendizes}

Docente - Veinte puntos. Después van encerrar con la proba del simulado, por eso es importante que hagan todas las tareas ahora.

Aprendiz.- (inint.) nós somos super ...

A atitude do docente, nos excertos 2 e 3, ratifica a postura dos aprendizes de somente realizarem atividades se tiverem algo em troca, neste caso, pontos para o bimestre. É notório, que o uso da avaliação para mobilizar interação dos aprendizes não se constitui de atitude que reforce o trabalho com a leitura do texto literário.

Entendo, assim, que o texto literário seria um recurso a mais que pode ser usado pelo docente, porém não o único; e, também, que a atividade desse docente não se limitaria somente ao momento da sala de aula. Antes disso, ele deveria pensar sobre as necessidades dos aprendizes e os objetivos a serem alcançados durante a aula, para depois definir o quê e como ensinar através da atividade proposta. Segundo Zilberman (2003, p. 28), "ao professor cabe o desencadear das 
múltiplas visões que cada criação literária sugere, enfatizando as variadas interpretações pessoais", ou seja, as percepções e a leitura que cada discente faz sobre o texto literário pode ser motivada ou não pelo docente, de acordo com sua prática docente.

No excerto a seguir, o docente apresenta uma postura que não contribui para uma construção efetiva do ato de ler em LE com o uso do texto literário. O aprendiz 1, do primeiro excerto, apresenta uma dúvida lexical e o docente já assume uma atitude prescritiva de responder diretamente à solicitação, sem possibilitar uma pesquisa no dicionário ou uma interação com os demais componentes do grupo de trabalho.

\section{Excerto 3 - Grupo 3}

Aprendiz 1.- Docente, paloma é pomba, né?

Docente - Sim.

O aprendiz 1 solicita a presença do docente e em forma de exclamação, executa uma pergunta sobre a interdição ocorrida no conto. Assim como, no excerto 3, o docente responde diretamente sem suscitar uma reflexão sobre os aspectos do conto e sua relação com o questionamento proposto pela atividade.

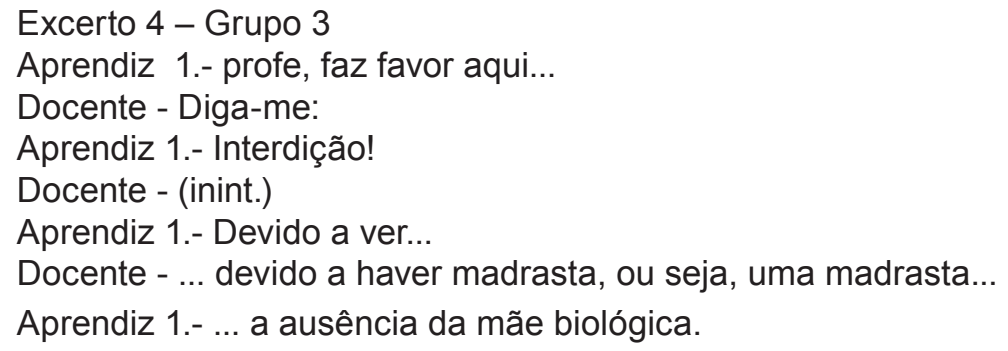

Percebe-se que a atitude do docente impossibilita uma abordagem que favoreça a construção de significados no momento da leitura, isso nos remete a uma concepção de leitura que não privilegia a interação autor - leitor - texto (CORACINI, 2002).

No excerto abaixo, analiso uma sequência de interação entre os integrantes do grupo tentando responder às questões referentes ao conto "Hansel y Gretel", apresentando as inferências realizadas frente aos conhecimentos adquiridos em outros contextos.

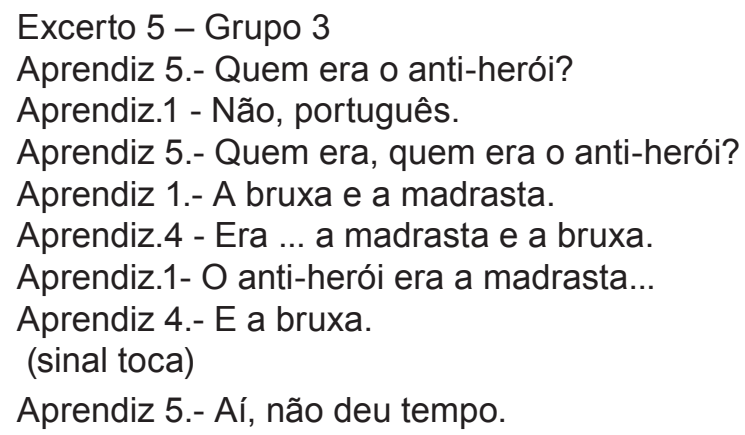

No trecho acima, observei que a interação entre os aprendizes para compor uma resposta coerente com o questionamento proposto. $\mathrm{O}$ uso do conhecimento prévio foi essencial para resolução da questão.

Na sequência, destaco um excerto com uma interação da aluna em espanhol, intensificando com o riso o nervosismo em falar na língua estrangeira. 


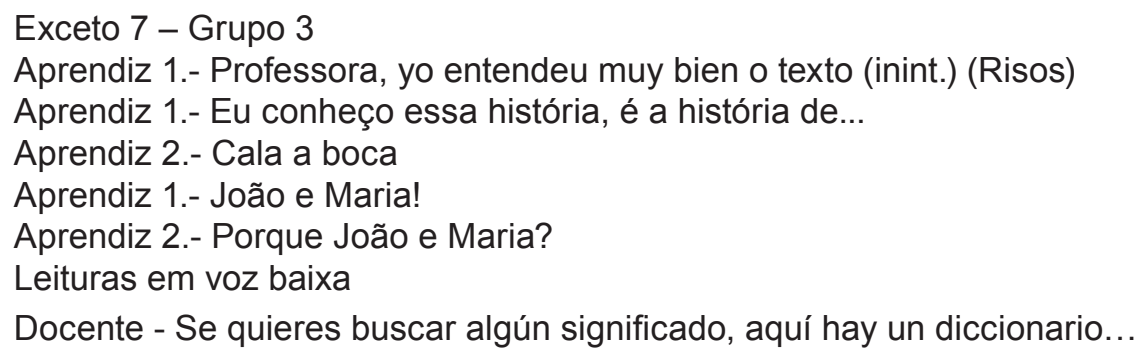

Assim, além dos modos de significação em LE, existe o "desafio de falar em outro universo fonético", pois há todo um trabalho de articulação do aparelho fonador para conseguir a emissão de outros sons desconhecidos, surgindo as "dificuldades" de aprendizagem. O enfoque de que a língua tem uma dupla escala é defendido por C. Melman (apud SERRANI-INFANTE, 1997) quando afirma que ao falar outra língua se quer guardar a música da Língua Materna, assegurando assim, a identidade.

$\mathrm{Na}$ situação descrita, faltou uma intervenção docente que suscitasse uma discussão sobre o conhecimento prévio do aprendiz 1 sobre o texto em língua portuguesa, enriquecendo a compreensão textual do grupo.

Igualmente, destaco abaixo, outro momento em que os próprios aprendizes conseguem responder a uma dúvida de cunho lexical, com o auxílio de discussão coletiva no grupo.

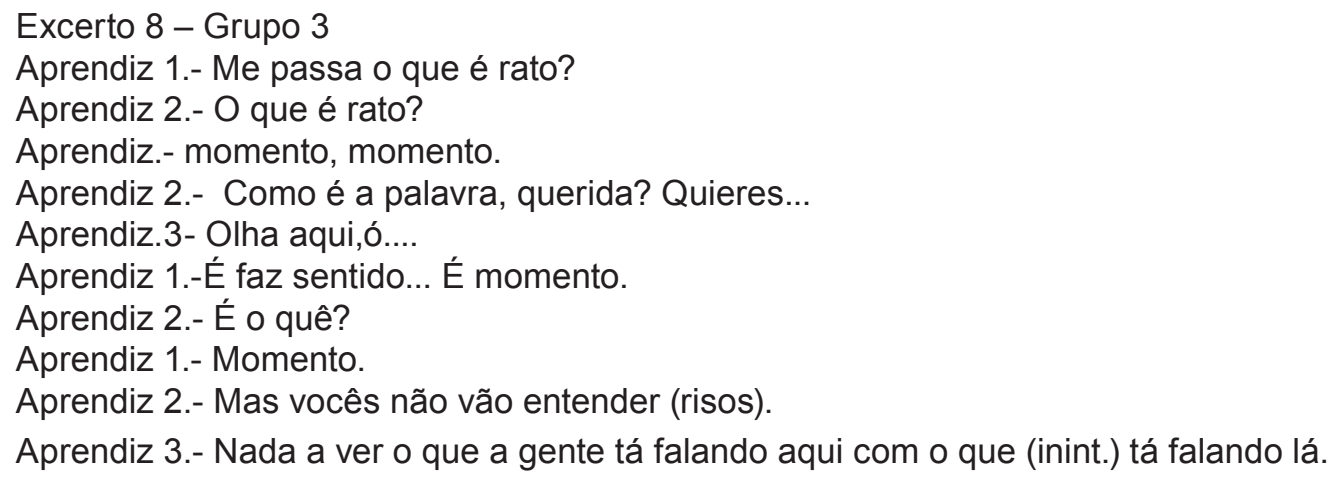

Tal atitude reforça o uso do trabalho coletivo, para construção de significado durante o processo de leitura em Língua Estrangeira. Nas gravações, houve intervenção dos aprendizes e do docente no que se refere à resolução das questões propostas pela atividade.

\section{5 | CONSIDERAÇÕES FINAIS}

Para elucidar as hipóteses, sobre o trabalho com proposta interacional e de que uma boa experiência didática com o texto literário pode reverter a imagem anteriormente construída, de que é possível um trabalho lúdico e produtivo com o uso do texto literário, para tanto, utilizei a atividade didática. Essa hipótese foi confirmada, embora a estrutura do próprio currículo e os horários de aulas da escola tenha dificultado a aplicação da atividade, já que a dinâmica da escola no que se refere a horários não poderia ser modificada em função da atividade de língua estrangeira.

Quanto à aplicação da atividade didática, destaco as seguintes conclusões:

a) os aprendizes participaram ativamente nas atividades propostas, mesmo sem entenderem o seu real objetivo, o que foi possível reconhecer em atitudes como a participação no processo de inferência inicial dos grupos, nos questionamentos realizados entre os próprios aprendizes que compunham os grupos na intenção de resolver as atividades propostas e, finalmente, nas 
LEITURA EM LÍNGUA ESTRANGEIRA | Maria Francisca da Silva e Maria Mercedes R. Quintans Sebold

atividades respondidas por escrito por alguns grupos, entregues ao final da aplicação da atividade didática;

b) o processo de leitura e compreensão dos contos mobilizou questionamentos durante a aplicação em sala de aula, com intervenções por vezes prescritivas por parte do docente, ou simplesmente, o aprendiz respondia as indagações com os dados superficiais constantes no conto, sem o uso de inferências mais elaboradas sobre os contos lidos.

Percebe-se que as respostas curtas revelam uma dificuldade do aprendiz com as perguntas relativas a aspectos específicos do texto literário, tais como: estrutura da narrativa a partir de elementos que compõe a narrativa (introdução / trama / epílogo), interação quanto ao ponto de vista em relação a outras possibilidades para o TL (inferência sobre outro final para o conto), possivelmente atrelada a pouca recorrência de atividades desse cunho em sala de aula.

Foram frequentes as intervenções por parte dos aprendizes, no sentido de buscarem uma resposta "certa" com o professor, como se as respostas obtidas por eles, não imprimissem confiabilidade e fossem desconsideradas numa possível correção. A liberdade de inferir sobre os significados que a leitura do conto poderia suscitar torna-se insuficiente diante da postura ou de resposta prontas ou de respostas com monossílabos do tipo "sim" ou "não" que não destacam o grau de entendimento sobre o texto.

É notória, a complexidade da função docente de língua estrangeira, pois a mudança de paradigma de trabalho com textos literários não é fácil, haja vista, que tanto docentes quanto aprendizes costumam trabalhar com procedimentos tradicionais baseados em leitura em voz alta do texto pelos aprendizes e tradução realizada pelo professor. Outra situação é a não importância dada à aula de espanhol língua estrangeira descaracterizando o papel da disciplina de subsidiar espaço de leitura e produção em língua estrangeira.

Diante dos dados apresentados, destaco principalmente a postura tomada pelo docente para encaminhamento da atividade didática e a postura dos aprendizes diante da proposta de leitura, o que de certo modo, trouxe reflexões mencionadas. Isto remete a hipótese, inicialmente aventada,que se referia à postura dos alunos frente à leitura do TL. A primeira, era que a experiência com o texto literário se restringe à escola para fins de avaliação; e a segunda, era que uma boa experiência didática com o texto literário facilita a aprendizagem em espanhol língua estrangeira.

Para elucidar a primeira hipótese, usei como recurso a entrevista Sociolinguística antes da aplicação da atividade, comprovando através dos discursos que a experiência com o texto literário se restringe à escola para fins de avaliação. Essa afirmativa é fundamentada pelas respostas obtidas que revelaram uma prática cotidiana de leitura que fosse capaz de mobilizar aspectos através do encantamento e o envolvimento com o texto literário. Em alguns casos somente durante o processo avaliativo surgiam textos dessa natureza. A constante ênfase em aspectos que denotassem facilidade de entendimento durante a leitura, suscita a necessidade de uma prática mais constante de textos com abordagem didática que mobilize outras habilidades, assim como, o gosto pela literatura tanto materna quanto estrangeira.

Em outros termos, finalizo tocando na questão central deste trabalho, o papel do docente frente ao encaminhamento de atividades de leitura. É notória, a implicação do docente na condução de atividades que possibilitem a compreensão leitora, mediando o processo de reflexão, suscitando as informações prévias - já possuídas pelo discente, através do seu próprio conhecimento de mundo- com as informações novas, criando novos espaços de aprender. Desse modo, a ação didática contribuirá para a formação leitora e reflexiva de seus aprendizes, assim como amplia as possibilidades de aprendizagem em língua estrangeira. 
LEITURA EM LÍNGUA ESTRANGEIRA | Maria Francisca da Silva e Maria Mercedes R. Quintans Sebold

\section{Referências}

CHARAUDEAU, P. Linguagem e discurso: modos de organização. Tradução Ângela M. S. Côrrea, Ida Lúcia Machado. São Paulo: Contexto, 2009.

CORACINI, M.J.R.F. (Org.). O jogo discursivo na aula de leitura. 2. ed. Campinas: Pontes, 2002.

DAHBAR, Sergio. Wikipedia. Disponível em: <http:// www.esacademic.com/dic.nsf/eswiki/1429344>. Acesso em: 20 jan. 2010.

Voces nuevas: narrativas. Caracas: Centro de Estudios Latinoamericanos Rómulo Gallegos, 1983.

DAHER, M. del C.F.G. Quando informar é gerenciar conflitos: a entrevista como estratégia metodológica. The ESPecialist., São Paulo: CEPRIL/EDUC, v. 19, 1998.

DEMO, P. Pesquisa: princípio científico e educativo. São Paulo: Cortez, 1992.

Pesquisa e construção de conhecimento. Rio de Janeiro: Tempo Brasileiro, 1996.

KATO, M. A. No mundo da escrita: uma perspectiva psicológica. 7. ed. São Paulo: Ática, 2010.

. O aprendizado da leitura. 6. ed. São Paulo:

Martins Fontes, 2007.

KLEIMAN, A. Texto e leitor: aspectos cognitivos da leitura. 2. ed. São Paulo: Pontes, 1992.

MAINGUENEAU, D. O contexto da obra literária: enunciador, escritor, sociedade. Tradução Marina Appen-

zeller. 2. ed. São Paulo: Martins Fontes, 2001. (Coleção leitura e crítica).

MARCUSCHI, L. A. Produção textual, análise de gêneros e compreensão. São Paulo: Parábola Editorial, 2011.
MOITA LOPES, L. P. Discursos de identidade na sala de aula de leitura de língua materna: a construção da diferença. In: SIGNORINI, I. (Org.) Língua(gem) e identidade: elementos para uma discussão no campo aplicado. Campinas: Mercado de Letras, 2002.

PROPP, V. Morphologie du conte. Paris: Seuil, 1970.

ROCHA, D.; DAHER, M. del C.; SANT'ANNA, V. L. de A. A entrevista em situação de pesquisa acadêmica: reflexões numa perspectiva discursiva. Polifonia, Cuiabá, v. 8, n. 8, 2004.

SERRANI-INFANTE, S. Discurso e aquisição de segundas línguas: proposta AREDA de abordagem. Porto Alegre: UFRGS, 1997. (Coleção ensaios).

SERRANI, S. Discurso e cultura na aula de língua: currículo - leitura - escrita. Campinas: Pontes, 2005.

SILVA, M. F. O uso do texto literário no ensino de espanhol como língua estrangeira. In: CONGRESSO INTERNACIONAL DE PROFESSORES DE LÍNGUAS OFICIAIS DO MERCOSUL, 1.; ENCONTRO INTERNACIONAL DE ASSOCIAÇÕES DE PROFESSORES DE LÍNGUAS OFICIAIS DO MERCOSUL, 1., 2010, Foz do Iguaçu. Anais... Foz do Iguaçu: UNIOESTE, 2010. p.740-749.

. Uma experiência de leitura do gênero "conto" nas aulas de espanhol língua estrangeira numa escola pública de Roraima. 2012. 267 f. Dissertação (Mestrado em Letras Neolatinas) - Faculdade de Letras, Universidade Federal do Rio de Janeiro, Rio de Janeiro, 2012.

ZILBERMAN, R. (Org.). A leitura e o ensino da literatura. 2. ed. São Paulo: Contexto, 2003. 